\title{
Research on Mountain City Mountain and Water Repair Strategy
}

\author{
Deng Hong ${ }^{1, *}$, Long Junjie ${ }^{2}$ \\ ${ }^{1}$ Department of Landscape Architecture, Faculty of Architecture and Urban Planning, Chongqing University, Chongqing, China \\ ${ }^{2}$ Department of Landscape Architecture, Faculty of Architecture and Urban Planning, Chongqing University, Chongqing, China
}

\begin{abstract}
The natural ecological environment is not only the basic condition of our human existence, but also the foundation of urban construction. The natural ecological environment restricts the development of cities. However, the mountains and water bodies of mountainous cities have been damaged to varying degrees in the past urban construction. Through the analysis of the current water bodies and mountains in mountainous cities, this paper puts forward the strategies for the restoration of mountains and water bodies, so as to realize the overall restoration of urban ecology.
\end{abstract}

\section{Introduction}

The complex terrain and landform of mountainous city not only constitute the unique style and appearance of the city, but also exist some problems such as ecological fragility, sensitivity, low disaster resistance ability and poor environmental carrying capacity.

In the process of the western development strategy, the mountainous cities are also rapidly urbanized. Many areas have carried out "destructive" construction regardless of the topography and natural ecological conditions, even at the cost of "pushing mountains and filling lakes". These greedy and push-down development and construction methods have caused habitat damage and ecological imbalance in mountainous cities, and even caused natural and engineering disasters.

Compared with plain areas, mountain cities face more prominent contradiction between protection and development, and they have more fragile and sensitive ecological environment compared with plain areas. The fragile and sensitive ecological environment of mountainous city is particularly prominent in the hilltop, river area and gully area. Therefore, the balance between development and protection should be the first problem to be solved in the design.

\section{Sstatus issue}

\subsection{Mountain problem}

The mountains in the mountainous city is not only the skeleton of the entire city's ecological network, but also an important component of the intersection of the city and mountain culture. However, in the past few decades, mountain ecosystems have been degrading at an unprecedented speed and scale. The restoration of the ecological functions and forms of damaged mountains has become one of the problems that must be solved in the process of urban construction and development.

In terms of external mountains, the outer mountains outside the mountainous city are large and green, but the lack of interaction between mountains. Although the cliff line has a good high-point view, the landscape is overlooking the landscape, and the city's balcony is missing. The mountains in the urban district are often small, the slope is destroyed, and the stone is exposed, and there is a risk of falling to pedestrians and driving safety. The original vegetation is destroyed, and the gravel is urgently needed. The slope is seriously destroyed, the sand is bare, the protective green space on the slope is caused by the residential vegetables, auto repair plants, car washings and other erosion.

\subsection{Water problem}

The water and waterfront space in the city are not only significant in the improvement of urban ecology, can reduce urban disorder and pollution problems in the city, and the identity of urban style and external image display. And windows. However, because of the complex landform conditions of the mountain city, it is easy to show soil erosion, and in the past urban construction, urban administrators neglect water pollution, ecological vegetation and shoreline There are many problems such as damage, so the ecological function of urban water bodies is severely damaged and has gradually lost their ecological benefits for urban environment and climate. 


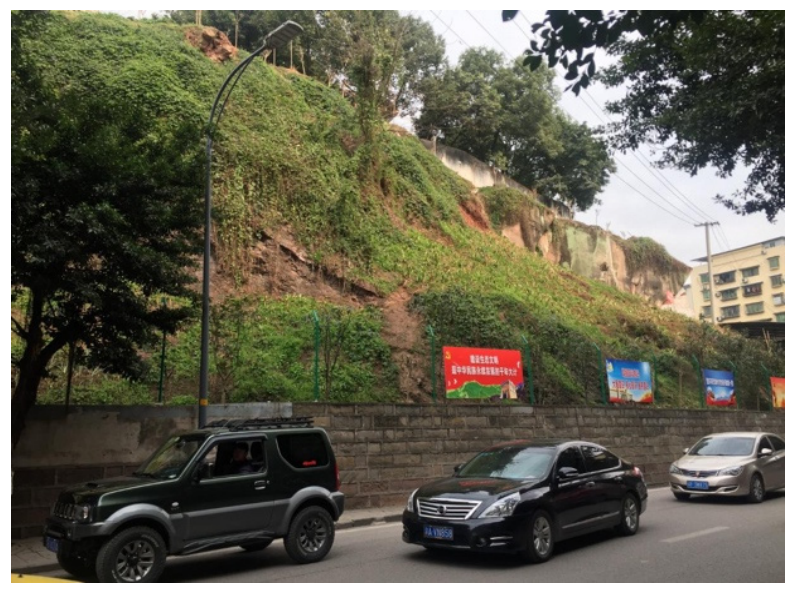

Fig. 1. Mountain damage status

According to field investigations, there are two main problems in mountainous cities: water quality and shoreline. Because the water body is in a closed state, the renewal cycle is long and the self-purification ability is low, and Chongqing is a subtropical monsoon humid climate, it is very easy to breed algae and appear "water bloom" phenomenon. In addition, the urban water bodies are surrounded by various types of urban construction land The surface runoff formed by rainwater during rainfall washes the surrounding buildings and roads, and brings various pollutants on the ground into the waters, directly or indirectly causing water pollution. The main pollutants are organic matter and nutrients from grassland and nursery.

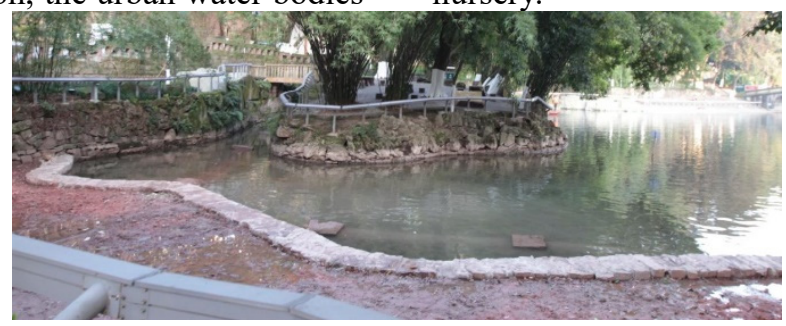

Fig. 2. Water damage status

\section{Repair strategy}

Mountain and water in the mountain city are important elements in their ecological environment. However, there are many problems in the current situation of mountains and water, how to make meticulous restoration and protection of mountains and water are important for urban public space quality. According to the specific problems of the mountains and water bodies in the mountainous city, the specific problems of the mountains and water bodies are proposed, and the specific repair and renovation strategies are proposed below.

\subsection{Mountain Repair: Increase urban view balcony, repair damaged hill ecosystem}

\subsubsection{Combined with the cliff line distribution to increase the landscape balcony, providing public viewing}

The city balcony refers to the construction of the mountain, and uses the landing space in Lingjiang, the slope or the roar break. It is possible to overlook the platform of viewing. It is a unique urban public space in the public space in the mountain city. The outside of the mountainous city is often used in the background of large mountains. It provides a good condition for the construction of the city balcony.

The construction of the city balcony can also enhance the interaction between mountains and cities to provide good outdoor event places and viewing experience. The construction of urban viewing balconies can mainly broaden the current situation of the current situation, increase the means of casual leisure platform, and the selection should choose a high terrain and convenient mountain cliff line, which should be able to serve a certain urban area. Public, and have superior viewing resources and conditions, good landscape vision.

All in all, there should be coordinated between the city balcony, the field of view, and the surrounding architectural features, and as a city public space, in order to ensure its publicity, it is necessary to meet the requirements of visual and path. 


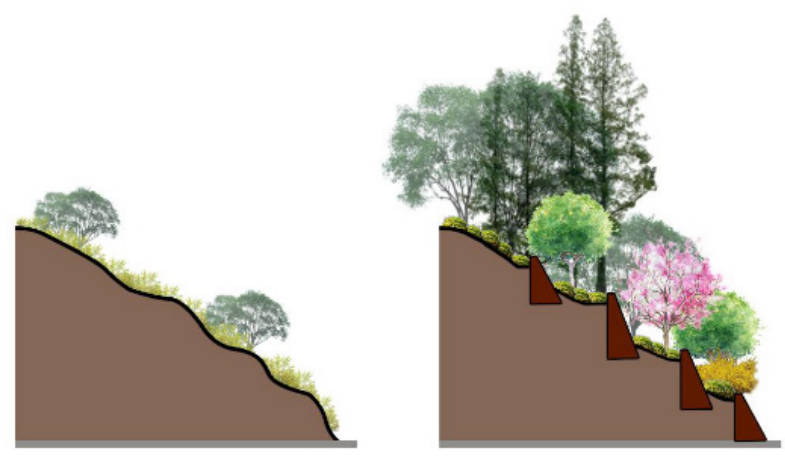

Fig. 3. Mountain restoration measures

\subsubsection{Restore its ecological function according to the damage between internal mountains}

For the mountains in the mountainous urban district, the usual volume is small, and in the past urban construction process, it is damaged by different levels, and there is even certain safety hazards, so the repair of the internal mountain should be restored to its ecological function.

It mainly repairs the mountain form in the city, and the local plant is repaired, and the local plants are selected for ecological restoration of vegetation. It is recommended to use the base of the hill to open the slope on the mountain. Built fish squamous pits, lower back flossing or planting soil, then planting plant green seedlings to occlude the damaged surface. The vegetation is relatively sparse, plants are made, and the enlargement of the mountain is covered. Clean up the temporary building in the range of the mountain green line and the vegetable field to restore the mountain ecological function; the mountains that are good for the current base conditions can be created as a mountain park, and the repaired mountain is injected into the corresponding green land according to the nature of the green land. Meet urban requirements and public demand.

\subsection{Water repair: source control water quality, shoreline, community repair water body}

The repair of the water body mainly includes two aspects, one is to use the sponge city for source control, relieve the pollution of the rains on the water body of the lake, and the second is through the shoreline, the community repair the water body itself, enhance its ecological function and environmental quality.

\subsubsection{Using Sponge City for source control}

Most of the mountainous city is more artificial water, because there is no upper river hydrating, the water source is from the runoff of rainfall and rainfall flushing ground, so the key point for the water repair in the district is to control the source of the source. To the full process of lake water to ensure self-purification from the source to the water.

Specific measures to introduce sponge city construction, planning rainwater gardens, and planning rainwater wetlands along the water body. The rainwater garden has purified filtration, soil and water reducing effect. By covering the bottom with soil and planted contaminant adsorption, natural ecological reactions settle, dilute or remove contaminants in rainwater. The rainwater garden is focused on the green space around the green space, combined with the green space system, and use the park plaza to set the rainwater garden. The rainwater wetlands are set along the lake, and the rainwater, the rainwater garden combines the status of the pond, recess, and connects with the drainpipe network. At the same time, small rain gardens are set in the surroundings of urban public buildings, residential areas, commercial areas and industrial areas, and there are small rain gardens on both sides of the road to alleviate the pollution of rainwater.

\subsubsection{Repair the water through the shoreline}

In addition to the control of the source of the water, it is lacking a continuous and effective circulating system for the water body itself, while the surrounding plant communities lack maintenance, and the discuts are varied, lack effective tissue, etc., the repair of the water body itself focuses on the shore and aquatic group Two aspects are launched. Refuting repair mainly repairs shoreline, softened revetable, using stone, wood, plant or other water-based material instead of hard material to reinforce treatment, beautify the damaged shoreline, to ensure the waterstore, do not hinder the water body The substances in the middle are exchanged, improve groundwater supply and surface water quality.

Water body is purified by plants and microorganisms. Plant repair mainly uses the decomposition of hazardous pollutants during plant breathing and metabolism to relieve water pollution. Aquatic plants in the periphery of the water body and the internal planting effect, such as: white, beautiful banana, yellow flower thies, sandhara, reed, lamp grass, etc., these plants can not only absorb nitrogen, phosphorus elements, etc., but also effectively Purify the rent of water, and the plant group is lower than other processing methods. Microbiology is also one of the effective polluting means. After a large amount of water in the water body, the microorganism can decompose all kinds of pollutants, and the nitrogen, phosphorus in the water body has a good removal effect, and it is possible to achieve an increase in water to dissolve oxygen to achieve improvement of the goal of water quality. 


\section{Conclusions}

To sum up, the restoration of mountains in mountainous cities can be divided into two ways. The first is that landscape balconies can be set up to provide public viewing grounds for the external mountains; the second is to restore their ecological functions according to the different damage conditions of the internal mountains. The restoration of water bodies can also be divided into two ways. The first is to use sponge cities to control the source and alleviate the pollution of the water bodies of lakes caused by the initial rain. The second is to repair the water body itself through the shoreline and community.

\section{References}

1. Du, D.(2013) Research and prospect of river water environment health evaluation. J.Water Science and Engineering Technology, 01:16

2. Fei, W.J., Ding, J.Y.,Cao, Y.(2018)Applicability design of waterfront green space from flood discharge ditch to sponge garden.J. Chinese Garden,34:106-111

3. Li, G.Y., Cheng, C.,Zheng.J.Y.(2006)Discussion on ecological concept of waterfront landscape design.J. China Soil and Water Conservation, 11:53-54

4. Cheng, Y.F., Sun,D.P.,He,S.N.(2015)The influence of river improvement project on river ecological environment and its countermeasures .J.People's Yellow River,37:35-38 